\title{
Comparison of two intravenous sedation techniques for use in pediatric dentistry: A randomized controlled trial
}

\section{Porównanie dwóch technik dożylnej sedacji w stomatologii dziecięcej - randomizowane badanie kliniczne}

\author{
Awj Rasheed Hammadyeh ${ }^{1, A-F}$, Mohamed Kamel Altinawi ${ }^{1, A, F}$, Faten Rostom ${ }^{2, A}$ \\ ${ }^{1}$ Department of Pediatric Dentistry, Faculty of Dentistry, Damascus University, Syria \\ ${ }^{2}$ Department of Anesthesia and Reanimation, Faculty of Medicine, Damascus University, Syria \\ A - research concept and design; $\mathrm{B}$ - collection and/or assembly of data; $\mathrm{C}$ - data analysis and interpretation; \\ $D$ - writing the article; $E$ - critical revision of the article; $F$ - final approval of the article
}

Address for correspondence

Awj Rasheed Hammadyeh

E-mail: aoj.star@hotmail.com

Funding sources

None declared

Conflict of interest

None declared

\section{Acknowledgements}

The authors are grateful for the financial support provided by the Faculty of Dentistry and the Department of Anesthesia and Reanimation, Faculty of Medicine, Damascus University, Syria.

Received on March 10, 2019

Reviewed on May 11, 2019

Accepted on June 7, 2019

Published online on October 9, 2019

Cite as

Hammadyeh AR, Altinawi MK, Rostom F.

Comparison of two intravenous sedation techniques for use in pediatric dentistry: A randomized controlled trial. Dent Med Probl. 2019;56(4):337-341. doi:10.17219/dmp/109929

DOI

$10.17219 / \mathrm{dmp} / 109929$

Copyright

๑ 2019 by Wroclaw Medical University

This is an article distributed under the terms of the

Creative Commons Attribution 3.0 Unported License (CC BY 3.0)

(https://creativecommons.org/licenses/by/3.0/)

\begin{abstract}
Background. Psychological methods are the preferred behavior management techniques (BMTs) for children in the dental clinical set. However, sometimes they are not successful. On such occasions, pharmacological methods can be good alternatives. Intravenous sedation is one of these methods, which are very useful in behavior management. It is highly effective when applied appropriately.

Objectives. The aim of this study was to evaluate the efficacy of intravenous sedation using dexmedetomidine in comparison with ketamine and atropine in uncooperative children during dental treatment.

Material and methods. The study was performed on 40 healthy uncooperative children aged 2-6 years. They were equally and randomly divided into 2 groups: group D - intravenous dexmedetomidine with a loading dose of $1 \mu \mathrm{g} / \mathrm{kg}$ body weight (b.w.), which was followed by $0.2 \mu \mathrm{g} / \mathrm{kg}$ b.w. $/ \mathrm{h}$ via continuous infusion; and group $\mathrm{K}$ - intravenous ketamine $2 \mathrm{mg} / \mathrm{kg}$ b.w. with atropine $0.01 \mathrm{mg} / \mathrm{kg} \mathrm{b.w.} \mathrm{Vital} \mathrm{signs,}$ recovery time and adverse effects were all recorded. Behavior was also evaluated using the Ohio State University Behavioral Rating Scale (OSUBRS).

Results. Statistically significant differences appeared in the degree of behavior between the 2 groups $(p=0.03)$. Group D did better than group K. The mean recovery time was shorter in group $D$ than in group $K$, but there were no statistically significant differences $(p=0.12)$. No side effects, episodes of cardiovascular or respiratory instability were reported in either group.

Conclusions. The use of intravenous sedation in managing uncooperative children is more effective with dexmedetomidine than with ketamine. The addition of atropine as an adjunct to intravenous ketamine sedation helps in preventing complications.
\end{abstract}

Key words: behavior, ketamine, dexmedetomidine, intravenous sedation Słowa kluczowe: zachowanie, ketamina, deksmedetomidyna, dożylna sedacja 


\section{Introduction}

Uncooperative behavior is the greatest challenge faced by pediatric dentists in daily practice. It can be a barrier to completing dental treatment or providing quality care. ${ }^{1,2}$ Generally, most of the children showing a lack of cooperation or fears should be managed by behavioral management techniques (BMTs). However, the use of pharmacological methods, like conscious sedation or general anesthesia, is required in some children who are unable to tolerate dental procedures despite the use of all gentle psychological methods.,

Among the drugs used for conscious sedation, one can mention ketamine, which is a phencyclidine derivative and provides amnesia and dissociative sedation, associated with an analgesic effect by blocking $\mathrm{N}$-methyl-D-aspartate receptors, without the loss of consciousness when given in appropriate doses. ${ }^{5}$ When ketamine is administered alone intravenously, it produces an adequate sedative effect. However, it may have different side effects, ${ }^{5}$ including hallucinations and nightmares during the recovery, ${ }^{6}$ as well as nausea, vomiting and excessive salivation, which may lead to potential coughing and laryngospasm. ${ }^{7}$

Dexmedetomidine is a potent, highly selective alpha-2 agonist that has sedative and analgesic effects. ${ }^{8}$ It acts on adrenoceptors in many tissues, including the nervous, cardiovascular and respiratory systems. ${ }^{9}$ When dexmedetomidine is administered within the recommended doses provided by the clinical guidelines, it results in dose-dependent analgesia with no accompanying respiratory depression. ${ }^{10}$ Some researchers even claim that the results of the action of dexmedetomidine resemble normal sleeping due to its alpha-2 agonist effect on the sympathetic system. ${ }^{11}$

Although there has been a lot of research on various drugs used individually and/or in sort of a combination (a cocktail) to achieve sedation in children, the 'golden' sedative drug - with better outcomes, a higher impact (but unquestionably safe) and with fewer side effects - is still being sought. ${ }^{12}$ Consequently, the present randomized controlled study was conducted to evaluate the efficacy and safety of intravenous sedation with dexmedetomidine in comparison with ketamine administered with atropine in uncooperative children aged 2-6 years during dental treatment. It is worth mentioning that this age group is widely considered to be the most difficult to manage in pediatric dentistry.

\section{Material and methods}

In this randomized controlled study, ethical and licensing approvals were obtained from the related specific review board (the number of the ethical approval is 2088, dated October $7^{\text {th }}, 2017$, and all parents gave informed written consent. This trial was carried out from November 2017 to January 2019.
The study consisted of 40 healthy (according to the American Society of Anesthesiology (ASA) scale, ASA I) children aged 2-6 years, requiring dental treatment (pulpotomy) under conscious sedation for exhibiting negative and definitely negative behavior on the Frankl scale. ${ }^{13}$ Each child was assessed by a pediatric dentist prior to the sedation procedure. Moreover, preoperative medical questionnaires were completed by the children's parents or guardians with the help of the dentist.

The exclusion criteria embraced any children with known allergy to the drugs used, and children with respiratory infections or any systemic disease.

All the children were requested to fast preoperatively for $6 \mathrm{~h}$ (solid foods and nonhuman milk), $4 \mathrm{~h}$ (human milk) and $2 \mathrm{~h}$ (water and clear liquids). ${ }^{14}$ Baseline heart rate (HR), oxygen saturation $\left(\mathrm{SpO}_{2}\right)$ and blood pressure (BP) were recorded before any drug administration, at a 10-minute interval and at the end of the dental procedure. ${ }^{14}$ An intravenous (IV) line was inserted before the start of conscious sedation using EMLA ${ }^{\mathrm{TM}}$ cream (AstraZeneca, Wilmington, USA).

The children were randomized into 2 equal groups - group D and group K - using a computer-generated table of random numbers.

The children in group D received intravenous dexmedetomidine with a loading dose of $1 \mu \mathrm{g} / \mathrm{kg}$ b.w. administered over $10 \mathrm{~min}$, followed by $0.2 \mu \mathrm{g} / \mathrm{kg}$ b.w. $/ \mathrm{h}$ dexmedetomidine as continuous infusion using a syringe pump, until the desired level of sedation was achieved. ${ }^{15}$ Dexmedetomidine was prepared and diluted with $0.9 \%$ sodium chloride saline to obtain the required concentration $(4 \mu \mathrm{g} / \mathrm{mL})$; then, it was gently shaken to mix it well prior to administration. ${ }^{15}$

In group $\mathrm{K}$, the children received intravenous ketamine hydrochloride $2 \mathrm{mg} / \mathrm{kg}$ b.w. along with atropine $0.01 \mathrm{mg} / \mathrm{kg}$ b.w.

After the drug administration, the dental procedure was initiated and completed by an experienced pediatric dentist. All sedation procedures were handled by 1 anesthetist and all dental procedures were performed by 1 experienced pediatric dentist.

The sedation onset and recovery time were recorded, and also the behavior of each child during treatment was assessed by an external assessor using recorded videos according to the Ohio State University Behavioral Rating Scale (OSUBRS) (Table 1), which was also used by Hitt et al. in $2014 .^{16}$

Table 1. Ohio State University Behavioral Rating Scale (OSUBRS)

\begin{tabular}{|c|c|}
\hline Score & Behavior \\
\hline 1 & quiet behavior, no movement \\
2 & crying, no struggling \\
3 & struggling movement without crying \\
4 & struggling movement with crying \\
\hline
\end{tabular}


Adverse events were noted, if any existed, and then the children were discharged when full consciousness was regained and all vital signs were within normal ranges. The parents were contacted by telephone approx. $24 \mathrm{~h}$ postoperatively to check for any complications experienced by the children.

Data analysis was performed using the Mann-Whitney $U$-test and Student's $t$-test. The statistical package used for all data was IBM SPSS Statistics for Windows, v. 21 (IBM Corp., Armonk, USA). Statistical significance was defined as $p<0.05$.

\section{Results}

A total of 40 healthy children aged 2-6 years completed the study protocol and the dental procedures. They were comparable with respect to the demographic data (Table 2). With regard to age, weight, gender, and type of procedure, the differences were not statistically significant. Throughout the procedures and during the recovery, no episodes of oxygen desaturation, hypotension, airway obstruction, or bradycardia were noted in any of the children. Oxygen saturation was $\mathrm{SpO}_{2}>97 \%$ in both groups.

In the dexmedetomidine group, the behavior score according to OSUBRS was 1 (quiet behavior, no movement) in 11 children (55\%), 2 (crying, no struggling) in 4 children (20\%), 3 (struggling movement without crying) in 2 children (10\%), and 4 (struggling movement with crying) in 3 children (15\%). On the other hand, in the ketamine group, 9 children (45\%) had a score of 1, 2 children (10\%) had a score of 2 , the behavior score was 3 in 7 children (35\%), and 4 in 2 children (10\%).

The mean OSUBRS scores for both groups are presented in Table 3 . There were statistically significant differences between the 2 intravenous sedation groups in the mean OSUBRS scores as recorded by the external assessor during treatment (Table 3). Group D showed better behavior than group K ( $p=0.03$; the Mann-Whitney $U$-test).

Table 2. Characteristics of the patients

\begin{tabular}{|l|c|c|}
\multicolumn{1}{|c|}{ Characteristic } & \multicolumn{1}{|c|}{$\begin{array}{c}\text { Group D } \\
(\mathrm{n}=20)\end{array}$} & $\begin{array}{c}\text { Group K } \\
(\mathrm{n}=20)\end{array}$ \\
\hline $\begin{array}{l}\text { Ratio male:female } \\
\begin{array}{l}\text { Age [years] } \\
\text { mean } \pm \text { SD }\end{array}\end{array}$ & $10: 10$ & $9: 11$ \\
$\begin{array}{l}\text { Weight [kg] } \\
\text { mean } \pm \text { SD } \\
\text { Sedation time [min] } \\
\text { mean } \pm \text { SD }\end{array}$ & $14.9 \pm 9.1$ & $15.2 \pm 0.9$ \\
$\begin{array}{l}\text { Recovery time [min] } \\
\text { mean } \pm \text { SD }\end{array}$ & $24.41 \pm 4.74$ & $22.58 \pm 4.44$ \\
\hline
\end{tabular}

Group D - administered dexmedetomidine; group K - administered ketamine along with atropine; SD - standard deviation.
Table 3. Comparison of the behavior scores during the procedure

\begin{tabular}{|c|c|}
\hline \multicolumn{1}{|c|}{ Group } & $\begin{array}{c}\text { OSUBRS score } \\
\text { mean } \pm S D\end{array}$ \\
\hline $\begin{array}{l}\text { Group D } \\
(n=20)\end{array}$ & $1.2 \pm 0.6$ \\
\hline $\begin{array}{l}\text { Group K } \\
(n=20)\end{array}$ & $2.3 \pm 1.1$ \\
\hline
\end{tabular}

In this study, the mean recovery time for dexmedetomidine was shorter than that for ketamine $(15.13 \pm 2.4 \mathrm{~min}$ and $17.93 \pm 2.5 \mathrm{~min}$, respectively) (Table 2 ). However, there were no statistically significant differences according to Student's $t$-test; the $p$-value for this comparison was 0.12 (non-significant).

No serious side effects were noted, either during the procedures or in the recovery room. Also, no late complications were reported by the children's parents in the $24 \mathrm{~h}$ following the operation in either group.

\section{Discussion}

The ideal sedative for the outpatient dental clinic would be effective, easy to titrate, fast in onset and offset, predictable in response, able to preserve the airway tone, and inexpensive. Most importantly, it should exhibit minimal cardiovascular or respiratory effects, and minimal risk of the central nervous system (CNS) depression.

Dexmedetomidine has been shown to possess some of the desirable properties mentioned. Despite these excellent attributes, data regarding the use of dexmedetomidine in pediatric dentistry is still limited. ${ }^{17}$

Based on the present investigation, there is promising potential in the use of intravenous sedation techniques to overcome children's interfering behavior in the dental office. The outcomes of the present study indicate that both the intravenous sedation protocols used in this trial (with dexmedetomidine or with ketamine along with atropine) could provide effective and safe sedation for children undergoing outpatient dental procedures, still dexmedetomidine resulted in superior sedation in comparison with ketamine. Most children in the dexmedetomidine group (55\%) showed quiet behavior and no movement, i.e., score 1 according to OSUBRS. This superiority can be attributed to the pharmacological sedative and analgesic effects of dexmedetomidine. ${ }^{18}$ In a previous study by Hall et al., the authors reported that alpha- 2 agonists behaved differently from other sedatives due to their unique characteristics that make their action in inducing sedation closer to normal sleep, yet obtaining the level of consciousness sufficient to respond to orders. ${ }^{8}$ This is consistent with the results obtained in the present study.

There is no research in the dental field comparing the use of intravenous dexmedetomidine to ketamine with atropine. This is the first comparative study of its kind, 
especially with the dosage mentioned. Therefore, the results of the present study could not be compared with any other. Studies that resemble the present one the most were conducted in the medical field, and compared dexmedetomidine to ketamine alone. In our study, the use of dexmedetomidine led to an earlier recovery than ketamine, but this difference was not clinically or statistically significant. However, intravenous dexmedetomidine has a longer time of onset, and ketamine has the advantage of having a quicker onset. Similar results were found in a study conducted by Gyanesh et al., who reported that children in the dexmedetomidine group had an earlier awakening and discharge than those in the ketamine group, but this difference was statistically non-significant. ${ }^{19}$

Dexmedetomidine is a potent centrally-acting alpha-2 agonist, and its action is characterized by easy titrating and a quick recovery from sedation, actually mimicking some aspects of natural sleep, ${ }^{8,20}$ as the drug has a short half-life of $1.5-3 \mathrm{~h}$ after administering the intravenous doses, and because the main site of action of dexmedetomidine is the locus ceruleus rather than the cerebral cortex in the CNS. ${ }^{8,20,21}$

In the present study, the results of recovery time for ketamine were consistent with the clinical pharmacokinetics and pharmacodynamics of ketamine. It is an anesthetic that has a short acting time, so it is used mainly in children and elderly adults for short procedures. The later half-life of ketamine (beta phase) is $2.5 \mathrm{~h}$, making the awakening from anesthesia fast. ${ }^{22,23}$

In our study, no patients experienced serious adverse events in either of the sedation groups, nor did any require the termination of the procedure or the administration of any emergency medications. This finding supports the aspect of safety relating to the use of intravenous dexmedetomidine, ${ }^{24,25}$ and it is in accordance with the findings of several other studies that utilized intravenous dexmedetomidine. $^{26}$

It also confirms the benefit of the prophylactic co-administration of atropine (an anticholinergic) as an adjunct to intravenous ketamine sedation in children. This is consistent with many studies, which have reported that atropine counters the effects of some sedatives, like ketamine, and reduces hypersalivation, excessive secretion from the respiratory tract, nausea, and vomiting, ${ }^{27-29}$ which are the most common complications related to the use of ketamine. ${ }^{6,7,30}$

\section{Conclusions}

In summary, both dexmedetomidine and ketamine presented satisfactory and good sedation, and were effective in behavior management in children undergoing outpatient dental procedures, but intravenous sedation with dexmedetomidine proved to be more effective than that with ketamine. Although intravenous dexmedetomidine led to an earlier awakening than ketamine, this difference was not statistically or clinically significant. The addition of atropine as an adjunct to intravenous ketamine sedation in children prevents the occurrence of complications and adverse effects.

\section{ORCID iDs}

Awj Rasheed Hammadyeh (1) https://orcid.org/0000-0003-1769-4259 Mohamed Kamel Altinawi (1) https://orcid.org/0000-0002-5637-7320 Faten Rostom (1) https://orcid.org/0000-0002-4883-1001

\section{References}

1. Carter AE, Carter G, Boschen M, AIShwaimi E, George R. Pathways of fear and anxiety in dentistry: A review. World J Clin Cases. 2014;2(11):642-653.

2. Forehand R, Long N. Strong-willed children: A challenge to parents and pediatric dentists. Pediatr Dent. 1999;21(7):463-468.

3. Done V, Kotha R, Vasa AA, Sahana S, Jadadoddi RK, Bezawada S. A comparison of the effectiveness of oral midazolam $-\mathrm{N}_{2} \mathrm{O}$ versus oral ketamine- $\mathrm{N}_{2} \mathrm{O}$ in pediatric patients - an in-vivo study. J Clin Diagn Res. 2016;10(4):ZC45-ZC48.

4. Lourenço-Matharu L, Ashley PF, Furness S. Sedation of children undergoing dental treatment. Cochrane Database Syst Rev. 2012;3:CD003877.

5. Rai K, Hegde A, Goel K. Sedation in uncooperative children undergoing dental procedures: A comparative evaluation of midazolam, propofol and ketamine. J Clin Pediatr Dent. 2007;32(1):1-4.

6. Horiuchi T, Kawaguchi M, Kurehara K, Kawaraguchi Y, Sasaoka N, Furuya $\mathrm{H}$. Evaluation of relatively low dose of oral transmucosal ketamine premedication in children: A comparison with oral midazolam. Paediatr Anaesth. 2005;15(8):643-647.

7. Bui T, Redden RJ, Murphy S. A comparison study between ketamine and ketamine-promethazine combination for oral sedation in pediatric dental patients. Anesth Prog. 2002;49(1):14-18.

8. Hall JE, Uhrich TD, Barney JA, Arain SR, Ebert TJ. Sedative, amnestic, and analgesic properties of small-dose dexmedetomidine infusions. Anesth Analg. 2000;90(3):699-705.

9. Yuen VM, Hui TW, Irwin MG, Yuen MK. A comparison of intranasal dexmedetomidine and oral midazolam for premedication in pediatric anesthesia: A double-blinded randomized controlled trial. Anesth Analg. 2008;106(6):1715-1721.

10. Khan ZP, Ferguson CN, Jones RM. Alpha-2 and imidazoline receptor agonist. Their pharmacology and therapeutic role. Anaesthesia. 1999;54(2):146-165.

11. Talke P, Lobo E, Brown R. Systemically administered alpha2-agonistinduced peripheral vasoconstriction in humans. Anesthesiology. 2003;99(1):65-70.

12. Eskandarian T, Maghsoudi SH, Eftekharian H. Clinical evaluation of the effects of two types of oral combination of midazolam in sedating pediatric dental patients. J Dent (Shiraz). 2010;11(1):10-20.

13. Malamed SF, ed. Sedation: A Guide to Patient Management. $5^{\text {th }}$ ed. St. Louis, MO: Mosby; 2009:14-22.

14. Coté CJ, Wilson S; American Academy of Pediatrics, American Academy of Pediatric Dentistry. Guidelines for monitoring and management of pediatric patients before, during, and after sedation for diagnostic and therapeutic procedures: Update 2016. Pediatr Dent. 2016;38(4):E13-E39.

15. https://www.drugs.com/pro/dexmedetomidine-hydrochlorideinjection.html Accessed March 2, 2019.

16. Hitt JM, Corcoran T, Michienzi K, Creighton P, Heard C. An evaluation of intranasal sufentanil and dexmedetomidine for pediatric dental sedation. Pharmaceutics. 2014;6(1):175-184.

17. Mahmoud M, Mason KP. Dexmedetomidine: Review, update, and future considerations of paediatric perioperative and periprocedural applications and limitations. Br J Anaesth. 2015;115(2):171-182.

18. Corcuera-Flores JR, Silvestre-Rangil J, Cutando-Soriano A, LópezJiménez J. Current methods of sedation in dental patients - a systematic review of the literature. Med Oral Patol Oral Cir Bucal. 2016;21(5):e579-e586. 
19. Gyanesh P, Haldar R, Srivastava D, Agrawal PM, Tiwari AK, Singh PK. Comparison between intranasal dexmedetomidine and intranasal ketamine as premedication for procedural sedation in children undergoing MRI: A double-blind, randomized, placebo-controlled trial. J Anesth. 2014;28(1):12-18.

20. Al Taher WMA, Mansour EE, El Shafei MN. Comparative study between novel sedative drug (dexmedetomidine) versus midazolampropofol for conscious sedation in pediatric patients undergoing oro-dental procedures. Egypt J Anaesth. 2010;26(4):299-304.

21. Callado LF, Stamford JA. Alpha2A- but not alpha2B/C-adrenoceptors modulate noradrenaline release in rat locus coeruleus: Voltammetric data. Eur J Pharmacol. 1999;366(1):35-39.

22. Whalen TB. Anesthetics. In: Whalen K, ed. Lippincott $t^{\circledR}$ Illustrated Reviews: Pharmacology. $6^{\text {th }}$ ed. Philadelphia, PA: Lippincott Williams \& Wilkins; 2015:184.

23. https://www.drugs.com/pro/ketamine-injection.html Accessed March 3, 2019.

24. Kim HS, Kim JW, Jang KT, Lee SH, Kim CC, Shin TJ. Initial experience with dexmedetomidine for dental sedation in children. $J$ Clin Pediatr Dent. 2013;38(1):79-81.

25. Malhotra PU, Thakur S, Singhal $P$, et al. Comparative evaluation of dexmedetomidine and midazolam-ketamine combination as sedative agents in pediatric dentistry: A double-blinded randomized controlled trial. Contemp Clin Dent. 2016;7(2):186-192.

26. Akin A, Bayram A, Esmaoglu A, et al. Dexmedetomidine vs midazolam for premedication of pediatric patients undergoing anesthesia. Paediatr Anaesth.2012;22(9):871-876.

27. Bocskai T, Németh A, Bogár L, Pytel J. Sedation of children for auditory brainstem response using ketamine-midazolam-atropine combination - a retrospective analysis. Springerplus. 2013(1);2:178.

28. Kye YC, Rhee JE, Kim K, et al. Clinical effects of adjunctive atropine during ketamine sedation in pediatric emergency patients. Am J Emerg Med. 2012;30(9):1981-1985.

29. Bhatnagar S, Mishra S, Gupta M, Srikanti M, Mondol A, Diwedi A. Efficacy and safety of a mixture of ketamine, midazolam and atropine for procedural sedation in paediatric oncology: A randomised study of oral versus intramuscular route. J Paediatr Child Health. 2008;44(4):201-204

30. Wood MN, Manley MC, Bezzina N, Hassan R. An audit of the use of intravenous ketamine for paediatric dental conscious sedation. Br Dent J. 2015;218(10):573-577. 